EMERITA. Revista de Lingüística y Filología Clásica (EM)

LXXIV 2, julio-diciembre de 2006

pp. $259-288$

ISSN 0013-6662

\title{
LA NARRACIÓN DE LA BATALLA DE FARSALIA COMO DERROTA EN LUCANO*
}

\author{
JESÚS BARTOLOMÉ GÓMEZ \\ UPV/EHU \\ jesus.bartolome@ehu.es
}

En este artículo se estudia, en primer lugar, la definición de la batalla de Farsalia como derrota, y las consecuencias de esa elección: la relectura de las guerras civiles de modo opuesto a la que realizaron los poetas augústeos. En segundo lugar, se examinan los intertextos a los que el poeta recurre para demostrar el carácter injusto de dicha derrota. Para ello, Lucano, por un lado, se sirve del uso antifrástico de modelos épicos; por otro, acomoda el relato de la batalla culminante de su poema al diseño de las grandes derrotas romanas, siguiendo principalmente el modelo de Livio, introduciendo, sin embargo, modificaciones significativas respecto al esquema básico elegido.

Palabras clave: Épica; Lucano; Farsalia; intertextualidad; derrota.
This paper, firstly, studies the definition of the battle of Pharsalus as a defeat, and the consequences of that election: a new interpretation of the Roman civil wars opposed to that of the Augustean poets. Secondly, it examines the intertexts which the poet uses to demonstrate that it is a very unjust defeat. In order to achieve his aim, Lucan, on the one hand, makes an antiphrastic use of epic models, and, on the other, he adapts the account of the climactic battle to the narrative design of the most notorious Roman defeats, according to traditional patterns in historical writing, especially those of Livy's canonical descriptions, modifying, however, in a significant way, some elements of its pattern.

Keywords: Epic, Lucan, Pharsalia, Intertextuality, Defeat.

La representación de una batalla, debido a su propia naturaleza, requiere normalmente la elección - en ocasiones, una necesidad impuesta por las adscripciones de niveles distintos del escritor - de una perspectiva que determina la definición de su resultado como victoria o como derrota, fruto, y manifestación visible, de la decantación de las lealtades de quien la relata. La cuestión, sin importancia para un escritor romano cuando se trata de guerras externas, resulta, en cambio, comprometedora en el caso de una lucha civil: en primer lugar a causa del desgarro que supone una decisión de este tipo; en segundo lugar, si se opta por el bando vencido, en razón del peligro

Este artículo forma parte del proyecto de investigación UPV 05/133. Presentamos un esbozo de las líneas principales en una comunicación al XI Congreso de Estudios Clásicos titulada «Derrota y victoria en la Farsalia de Lucano» (Actas del XI Congreso de la SEEC, Madrid 2005, vol. II, pp. 777-84), queremos profundizar aquí en las cuestiones allí indicadas. 
que entraña recordar al vencedor el alto precio en sufrimientos de sus conciudadanos pagado por su victoria y la posición privilegiada de ella deriva$\mathrm{da}^{1}$; también por una tercera razón ligada a la anterior, el simple recuerdo de tales acontecimientos, más cuando son aún recientes, renueva un dolor profundo y recrea unos sufrimientos que han dividido a los ciudadanos y a los que el bando vencedor ansía poner fin, promoviendo, al menos de forma aparente, la reconciliación de la sociedad escindida ${ }^{2}$.

El largo período de guerras civiles, que culminará con la liquidación de la República y el establecimiento del régimen imperial, facilitó, debido a la inexistencia de un enemigo externo, pero también por causa de las simpatías de los escritores, la reflexión sobre la crudeza de la guerra y estimuló la comprensión del bando perdedor: la derrota cobra una presencia más sólida, y el vencido recupera, aunque sólo sea por la proximidad, la condición humana, de la que parece necesario despojarle para reducirlo a la exclusiva de enemigo. Así, en la Eneida, se dejan oír las razones del vencido, aunque su derrota se justifique en aras de un fin que éste no puede aceptar o comprender tan sólo desde el punto de vista humano, pues existen designios superiores que así lo determinan. Sin embargo, nunca antes, como en la Farsalia, la derrota y la causa vencida habían constituido la perspectiva desde la que se narran los hechos (D. Quint 1993, pp. 131-209). Como consecuencia de dicha elección, se cuestiona la legitimidad de la victoria en una guerra civil y, lo que es más, se declara la supremacía moral del vencido, hasta el punto de convertir la derrota en el resultado preferible de la lucha (uincere peius erat $)^{3}$, un planteamiento que obliga a reformular el código épico, y supone

1 Así se lo hacía saber Horacio a su amigo Polión advirtiéndole del peligro de escribir sobre la guerra civil, cuyas llamas aún no se habían extinguido (Od. II 1-8). E. Narducci (1965, 1986, 2002). La estrecha relación entre el poder imperial y las guerras civiles, de las que nace o surge y supone la liquidación de la república (libertas) hace que dicho tema, salvo de forma elogiosa o al estilo de Virgilio, no sea bien visto por el poder, y se considere peligroso el poner en evidencia la crueldad y barbaridades cometidas para desembocar en el imperio. C. Salemme (2000, p. 529; 2004, p. 56), por su parte, ilustra los riesgos, pero también la importancia de recordar estos sucesos del pasado, cuando indica que la evocación histórica es un modo de «participar, con pasión, en los acontecimientos del presente».

2 La reflexión sobre la maldad intrínseca de la guerra civil se manifiesta con frecuencia en Cicerón: Omnia sunt misera in bellis ciuilibus (Cicerón a Marcelo, Fam. IV 9.3; o Att. VII 14.3, Att. IX 7.4, Phil. II 15.37; y estará presente la expresión de sus amargas consecuencias en todos los autores de la época augústea. La obra de P. Jal (1963) sigue siendo imprescindible; para este punto en concreto, véanse las pp. 231-6 y el cap. II de la Tercera Parte.

3 De ahí también la calificación del vencedor como uictor iniquus (VII 40 y IX 139),

EMERITA (EM) LXXIV 2, julio-diciembre $2006 \quad$ pp. 259-288 ISSN 0013-6662 
un vuelco de la concepción tradicional romana de la guerra, que no asume la derrota $^{4}$. En su empeño Lucano desvela lo caduco de los mecanismos ideológicos tradicionales que sirvieron para justificar las victorias romanas: la equivalencia entre razón o justicia y victoria, poniendo en evidencia la falsedad del aparato ideológico que explicaba la instauración del régimen de Augusto $^{5}$. Consecuencia de la calificación del suceso como derrota es la profunda revisión de la historia de las guerras civiles, incluida la batalla de Accio.

\section{La caracterización como derrota}

El motivo fundamental de la decantación de Lucano se encuentra en la identificación de los vencidos con la causa de la libertad y de los vencedores con la tiranía, por lo que las consecuencias del desenlace fatal de un enfrentamiento entre los defensores de la esencia de Roma y quienes pretenden su destrucción no pueden ser sino lamentadas ${ }^{6}$.

La coincidencia con la perspectiva del bando perdedor se manifiesta mediante el recurso más obvio, el empleo reiterado del término clades en las múltiples intervenciones del poeta - con mayor frecuencia a lo largo del relato de la batalla decisiva (libro VII) ${ }^{7}$ - para definir el resultado de la lucha; más interesante, sin embargo, es la incardinación de la batalla referida en el interior de un ámbito de mayor alcance que expresa con precisión su magnitud: la comparación con las más famosas derrotas sufridas por Roma contra

próxima a lo expresado por Séneca (Ep. XIV 13): Potest melior uincere, non potest non peior esse, qui uicerit, que se encuentra por primera vez en Lucano, excepción hecha de Séneca, Epigr. 6.3 .

4 R. Heinze (1996 [1902], p. 34) había señalado las dificultades que tuvo que afrontar Virgilio al narrar la Iliupersis por boca de uno de los principales troyanos, nada menos que el ancestro de los romanos. «Enea, sopravvissuto a la catastrofe de la patria, ha lasciato le macerie di Troia per fondare altrove una nuova città. $\mathrm{Al}$ solo pensare una cosa del genere, un cittadino romano debe, per forza di cose, aver provato un profundo senso di vergogna». Por su parte, N. Rosenstein 1990, p. 138 señala al respecto: «Thus one might say the aristocratic ethos demanded above all that a general manifest a refusal to accept defeat».

5 Cf. F. Ahl 1993, pp. 133-7.

6 El trastorno de la "romanidad" que se produce con las guerras civiles (F. Ahl 1976, p. 230), se acentúa en el libro VII, el de la batalla decisiva. La transformación de la figura de Pompeyo en ese libro y sobre todo su retirada pone al descubierto los auténticos contendientes en la lucha (sed par quod semper habemus, /libertas et Caesar, VII 695-6).

7 El empleo del término clades sirve de instrumento de coherencia temática del poema (54 veces en la obra, 15 en el libro VII), cf. P. Esposito 1987, p. 112.

EMERITA (EM) LXXIV 2, julio-diciembre $2006 \quad$ pp. 259-288 ISSN 0013-6662 
un enemigo externo, especialmente la del Alia y la de Cannas, puntos de referencia para historiadores y poetas romanos, enfatiza la consideración de Farsalia. Los pasajes más sobresalientes los hallamos igualmente en este mismo libro: Cedant feralia nomina Cannael et damnata diu Romanis Allia fastis/ tempora signauit leuiorum Roma malorum, / hunc uoluit nescire diem (VII 408-11) ${ }^{8}$. Se trata de una denuncia del registro tradicional de la memoria romana, que, a un tiempo, cancela toda posibilidad de calificar los sucesos de Farsalia como una victoria, en contraposición a la valoración oficial ${ }^{9}$.

La comparación no se limita a definir el sentido de dicha batalla, sino que intensifica el grado negativo del acontecimiento. Por un lado, mediante la palabra de los propios contendientes, que declaran preferir un destino tan indeseable e infame, como el de los vencidos en las derrotas de Cannas y el Trebia ('o miserae sortis, quod non in Punica nati / tempora Cannarum fuimus Trebiaeque iuuentus', II 45-6), a la lucha en esta contienda; por otro, el narrador mediante la comparación expresa con Cannas (non illum Poenus humator / consulis et Lybica succensae lampade Cannae / conpellunt, VII 799-801). Por último, la intervención autorial (Non istas habuit pugnae Pharsaliae partes/ quas aliae clades..., VII 632-3) contribuye asimismo a acrecentar las dimensiones de Farsalia como derrota al comparar los resultados de esta lucha con los efectos de otros sucesos catastróficos sin especificar (aliae clades, v. 633). Todas las voces, por tanto, confluyen en un mismo punto. El efecto de la comparación magnificadora de Farsalia con las derrotas señaladas es demoledor, pues reinterpreta la historia oficial de Roma, y cancela, a diferencia de lo ocurrido en las derrotas con las que se compara, toda posibilidad de compensación mediante una victoria definitiva ${ }^{10}$. La trascendencia de la pérdida sufrida en Farsalia sólo alcanza parangón

8 P. Jal (1963, p. 440, y n. 11), basándose en los datos aportados por J. Gagé [Édition des R.G, 177], indica que los Fastos sí recogen Farsalia, pero además se señala como victoria: Maff.: hoc die Caesar Hispali uicit. Allif.: quod eo die uicit. Amit.: Fer. q.e.d. C. Caes. C. f. Pharsali deuicit. Ant: Diuus Iulius Phars. uicit. No hay que excluir, por otra parte, que la referencia a Alia en este pasaje constituya una alusión a Verg., Aen. VII 717 infaustum... Allia nomen.

9 J. Masters (1994, pp. 160-1) resume la cuestión de la falta de unanimidad sobre la consideración de la victoria de César. En referencia a sus triunfos, son valiosos los datos proporcionados por P. Jal 1963, pp. 441-3 y R. A. Gurval (1995, p. 20 ss.), quien compara dicha celebración con la de los triunfos de Octaviano.

10 Cf. C. Salemme 2004, 9-20.

EMERITA (EM) LXXIV 2, julio-diciembre $2006 \quad$ pp. 259-288 ISSN 0013-6662 
aceptable con una catástrofe de dimensiones cósmicas ${ }^{11}$.

En la alineación de esta batalla existe, no obstante una segunda vertiente de mayor trascendencia que la hasta aquí examinada: la inclusión de la batalla de Farsalia y Accio, como su punto inicial y final respectivamente, dentro de una misma secuencia o catálogo de sucesos nefastos de la guerras civiles, priva a ésta de la condición de victoria por antonomasia que, para la generación anterior, había adquirido. El ejemplo más significativo, porque contiene la enumeración de mayor extensión y porque remite por un lado a Virgilio (Ge. I 489-92) y, especialmente, a otros dos pasajes, uno de Propercio (II 1.27-34) y otro de Ovidio (Met. XV 826-8), se encuentra en el inicio del elogio de Nerón:

scelera ista nefasque

hac mercede placent; diros Pharsalia campos impleat et Poeni saturentur sanguine manes; ultima funesta concurrant proelia Munda; his, Caesar, Perusina fames Mutinaeque labores accedant fatis et quas premit aspera classes Leucas et ardenti seruilia bella sub Aetna (I 37-43) ${ }^{12}$

En ésta y en el resto de enumeraciones ${ }^{13}$, Farsalia recibe un tratamiento similar al de las demás grandes batallas de las guerras civiles, juzgadas todas ellas desde una misma perspectiva sin matices, con lo que supera la posible ambivalencia del mensaje de sus predecesores ${ }^{14}$, bien sea por seguir el cami-

11 Las referencias a la destrucción del universo menudean en el texto, por ejemplo: I 5-6, 72-80; II 2, 9-11, 290-5; V 228-30; VII 46, 89, 108-9, 133-8, 274-85; se trata de una forma reiterada en la caracterización de las guerras civiles, como demuestran los datos aportados por P. Jal (1963, pp. 281-4) y M. Lapidge (1979). Asimismo el enfrentamiento entre César y Pompeyo se plantea como un conflicto universal, cf. Hunink 1992, pp. 103-6.

12 La comparación de esta secuencia de Lucano con Propercio (II 1.25-36) y Ovidio (Met. XV 822-28) merece un estudio detallado que aquí nos es imposible realizar; baste decir que muestra, al menos de forma aparente -la interpretación irónica o seria de muchos de estos pasajes o de poemas dificulta la consideración unívoca-, divergencias considerables entre estos escritores y el poeta cordobés. Llama la atención el silencio sobre la guerra civil en la enumeración de los triunfos de César que incluye Ovidio (Met. XV 752-58).

13 Enumeraciones similares se repiten en V 478-9, y antes en I 678-95, igualmente en VII 867-72 o en X 65-73, donde se refiere a la intervención de Cleopatra en Accio.

14 La presentación, que antecede al pasaje citado, de la ruina de los pueblos circundantes de Roma como consecuencia de la guerra civil, lo opuesto al futuro que les vaticinaba Virgilio: At nunc semirutis pendent quod moenia tectis (Luc. I 24 ss. / Aen. VI 773-6) parece una contestación explícita al mantuano, pero el ejercicio intertextual es mucho más complejo, como señala E. Narducci (2002, pp. 167-9), pues a través de la evocación de pasajes como el lamento de Propercio (IV 10.27 ss.) por la decadencia de la Roma antigua, o el mismo Virgi-

EMERITA (EM) LXXIV 2, julio-diciembre $2006 \quad$ pp. 259-288 ISSN 0013-6662 
no que encontraba trazado de forma velada en los primeros planteamientos de los augústeos (Ge. I. 490-2, Prop. I 21, I 22, II 1), bien sea en franca contradicción con lo que los posicionamientos más tardíos de aquéllos parecen sugerir. ${ }^{15}$ Igualmente, deja poco espacio para la valoración, favorable a Augusto, de Accio como una guerra extranjera ${ }^{16}$. Pero la diferencia principal consiste en que dichos poetas no desdicen abiertamente su carácter de victoria ni abandonan como perspectiva dominante la del vencedor, mientras que Lucano, elige, para componer su epopeya de la derrota, la perspectiva del vencido.

La consideración de la batalla desde este punto de vista exige una narración particular, ya que no sirve a este fin ni el relato épico tradicional que ensalza la gloria del vencedor, ni el histórico dominante, que expone las razones que conducen a la victoria. Tales modelos resultan inservibles para su propósito, pero no puede prescindir de ellos, por lo que su estrategia consiste en utilizar de modo muy peculiar, por un lado, el código épico, mediante el empleo de modelos «inadecuados» o el uso antifrástico de algunos de sus recursos tipificados; por otro, el historiográfico, en un tipo concreto que poseía ya una configuración específica: el relato de derrotas, entre las que las causadas a Roma por Aníbal son los ejemplos más notables. Entre los intertextos épicos, por supuesto, el de Virgilio, sin ser el único, es omnipresente; entre los historiográficos, dos son de un valor particularmente considerable: el del relato de César, al que en parte desdice y desmiente, y el de Livio, del

lio por la de Ardea (VII 411 ss.), etc., induce a pensar que Lucano pretende hacer evidente la profecía de destrucción escondida en Virgilio. Resulta útil la consulta de M. Labate (1991), y más recientemente de A. Perutelli (2004) y D. Spencer (2005). En la misma dirección puede interpretarse la presencia de las familias más ilustres de Roma en medio de la batalla (Verg., Ge. II 169 y Aen. VI 824-25), cf. D. Gagliardi (1975, comm. ad VII 358-59).

15 No es posible definir una línea única en el tratamiento de Accio entre los distintos autores; tampoco mantuvieron una actitud idéntica a lo largo del tiempo. La valoración de dicha batalla es una cuestión compleja y su examen está fuera de nuestro propósito, por lo que remitimos al tratamiento que hace R. A. Gurval (1995), donde se encuentran los datos necesarios para seguir este complejo problema.

16 Es digno de destacar el esfuerzo de Lucano por enfatizar el carácter de lucha civil, frente a lo que ocurre en los relatos de la batalla de Accio entre los augústeos, empeñados en presentarla como una victoria sobre un enemigo externo: Virgilio, Aen. VIII, Propercio IV 6 (más dudas ofrece Horacio en Ep. 9 y $O d$. I 37 y Proprecio II 1). La repetición de términos como sanguis o cruor adjetivados con Romanus, Hesperius o Italicus en la batalla central insiste en la misma idea.

EMERITA (EM) LXXIV 2, julio-diciembre $2006 \quad$ pp. 259-288 ISSN 0013-6662 
que se sirve en diferentes modos ${ }^{17}$.

Con ello, el poeta demuestra que la derrota no encuentra explicación según los parámetros de la épica ni de la historia ${ }^{18}$, por lo que resulta imprescindible para dar cuenta de lo sucedido un tratamiento trágico (Codoñer 2003).

\section{El intertexto épico}

En el análisis del intertexto épico nos limitaremos a los pasajes que ilustran la falta de adecuación funcional de los modelos elegidos respecto a la condición de vencedor o vencido ${ }^{19}$.

La discordancia se observa en la identificación entre las figuras relevantes de una y otra obra desde la perspectiva señalada: por un lado, la establecida entre Eneas y Pompeyo ${ }^{20}$; por otro, la correspondiente a Turno y César. La relación entre Turno y Pompeyo, adecuada funcionalmente, resulta, debido a otras razones, inapropiada por completo, como veremos. Tales faltas de adecuación se encuentran en consonancia con otro marco más amplio de referencia intertextual, el mito de la Gigantomaquia y su utilización por los poetas de la época de Augusto y por Lucano.

El lamento de Pompeyo ante la imposibilidad de diferir la lucha, ya inminente: Quantum scelerum quantumque malorum/ in populos lux ista feret... / sanguine romano quam turbidus ibit Enipeus. (VII 113-6) ${ }^{21}$, evoca el profe-

17 Los rasgos que caracterizan las descripciones de batallas de Lucano respecto a Virgilio los resume en tres P. Esposito 1987, p. 37: 1) relato de tipo heroico-mítico en Virgilio, histórico-militar en Lucano; 2) Lucano hace suyos los procedimientos y técnicas de la historiografía; 3) con Lucano, el código épico se transforma, por fundirse, en cierto grado, con el de la historiografía. Las técnicas historiográficas (atención a las acciones de conjunto en vez de aristías, etc.) las analiza en p. 131 y ss.

18 Los dioses, que aseguran en la Eneida el éxito de la misión de su protagonista, no intervienen en la Farsalia de forma activa (D. Feeney 1991, p. 250 ss.), tan sólo se limitan a manifestar su voluntad coincidente con el destino; tampoco garantizan «la teleología imperial de Livio» (E. Fantham 2003, p. 229).

19 Probablemente encontremos aquí una muestra más de la pretensión de Lucano de explicitar lo que Virgilio dejó oculto o velado por la ambigüedad (la polifonía de Virgilio), idea que cobra cada vez más fuerza por encima del anti-virgilianismo enunciado por A. Thierfelder 1934, cf. E. Narducci 1979, 1985 y 2002, pp. 75-80, con bibliografía y resumen de la cuestión, y F. Delarue 1996, p. 218 ss.

20 E. Narducci 2002, p. 281, habla de un tipo de «Enea sconfitto», cf. también Íd. 1979, p. 113.

21 No olvidamos la reacción de Latino ante la petición de lucha de su pueblo (Verg., Aen. VII 624-640), que posee su importancia en la estrategia de exonerar a Pompeyo al concederle

EMERITA (EM) LXXIV 2, julio-diciembre $2006 \quad$ pp. 259-288 ISSN 0013-6662 
rido por Eneas cuando observa las armas en el cielo (VIII 520-39), con el que comparte el tono y el módulo estilístico. La poesía precedente se había servido de este símbolo para expresar el sentimiento de dolor ante el advenimiento de las guerras civiles ${ }^{22}$. Lucano interpreta precisamente en esa clave (referencia a la guerra civil y a la victoria de Augusto), el citado pasaje de la Eneida, y descubre lo que allí, en efecto, se encontraba, pero sólo insinuado o sutilmente velado. Los puntos diferenciadores se revelan entonces significativos $^{23}$. Pese a la conciencia clara de las consecuencias trágicas de la acción que va a emprender, el héroe troyano debe someterse a los designios divinos. Tal actitud, cuyo significado contiene elementos contradictorios, motiva la reacción de Lucano, que, como señala E. Narducci 2002, p. 306, veía en ella sobre todo, ambigüedad e hipocresía, por lo que pone en escena a un Pompeyo que destruye la ambivalencia señalando la culpabilidad de los dioses que apoyan a los impíos como causa de la inevitabilidad de la masacre que espera cumplimiento. Únicamente desde la posición de rechazo a la lucha civil - y, de forma prospectiva, en su condición de vencido -, desde la que toma la palabra Pompeyo, cuya figura, liberada de su realidad histórica, emerge transformada, el lamento puede ser sincero. La integración del texto virgiliano induce al lector a establecer entre ambos personajes, por encima de la proximidad aparente, una relación compleja que, además de cuestionar la validez del planteamiento virgiliano antes señalado, pone al descubierto la falsedad de la ecuación pietas-apoyo divino-victoria. La proximidad entre los personajes citados, e incluso la superioridad moral de Pompeyo en su lamento negándose a la lucha, hace más patente la contradicción con la condición opuesta de vencedor y vencido que uno y otro encarnan ${ }^{24}$.

Si continuamos la indagación en esa línea de referencias intertextuales, nos encontramos de forma inevitable con los modelos funcionalmente idén-

una estatus especial al margen de los contendientes, pero menor para nuestro propósito.

22 Cf. P. Jal 1963, p. 239. Aunque el pasaje de la Eneida no anuncie propiamente una guerra civil, se puede interpretar como símbolo de ella, como señala A. Barchiesi (1984, pp. 79-82).

23 En palabras de E. Narducci (2002, pp. 305-6): «el prodigio que determina la exclamación de Eneas vale a su vez como anuncio de la guerra ruinosa y como señal de la ayuda divina a los exiliados troyanos, de cuya victoria surgirá con el tiempo la potencia de Roma y el 'nuevo orden del mundo' (así como de la victoria de Augusto nacería una orden nuevo e imperecedero)».

24 La calificación del ejército cesariano: inpia plebes, v. 760, inpia signa, v. 838. no necesita comentario.

EMERITA (EM) LXXIV 2, julio-diciembre $2006 \quad$ pp. 259-288 ISSN 0013-6662 
ticos, es decir aquellos que cumplen el papel de derrotados, entre los cuales es lógico pensar que la figura de Pompeyo encuentre un mejor acomodo. Observamos, en efecto, la asimilación a los vencidos en la presencia de otro texto virgiliano, en este caso se trata del sentimiento de Turno antes del combate decisivo: di me terrent et Iuppiter hostis (Aen. XII 895) y sobre todo en el homérico que lo sustenta, donde se ofrecen los sentimientos de Héctor ante su final (Hom., Il. XXII 296 ss.) ${ }^{25}$. La identificación con la figura de Héctor no genera ningún tipo de dificultad; la de Turno, en cambio, resulta problemática. Si consideramos únicamente la condición de vencido y las cualidades dramáticas del texto virgiliano, que en el momento decisivo presta voz al sufrimiento del héroe rútulo, la incorporación del texto virgiliano es congruente, casi diríamos inevitable, pero si nos atenemos a la caracterización de citado personaje a lo largo de la Eneida, su disonancia dentro del nuevo contexto se hace patente, si bien el significado de dicha falta de adecuación coincide con el de la relación entre Pompeyo y Eneas: Lucano desea subrayar la distancia con el modelo propuesto, mostrando el conflicto inevitable al que conduce la delimitación de la identidad funcional de Pompeyo: un vencido que no merecía la derrota ${ }^{26}$.

Proporciona fuerza a este argumento una nueva secuencia de identificaciones paradójicas, conseguida mediante otra relación intertextual compleja que se mueve en las mismas coordenadas de significación, nos referimos a la representación de la aristía de César (Luc. VII 557 ss.) basada, de acuerdo con el análisis que hace W. D. Lebek (1976, pp. 254-60), en la de Turno (Aen. XII 324-82) ${ }^{27}$. La doble comparación, la de César con Belona y con Marte, símil que Virgilio sitúa en el inicio de la aristía citada del héroe rútulo, establece una identificación entre ambos; así parece demostrarlo la pre-

25 La diferencia reside, de acuerdo con E. Narducci 2002, p. 303, en la manifestación del engaño divino en el pasaje homérico y su ausencia en el de Eneida.

26 Los términos del lamento de Anquises en el momento de anunciar a Eneas el futuro enfrentamiento entre César y Pompeyo: Illae autem paribus quas fulgere in armis,/concordes animae nunc et dum nocte premuntur,/ heu quantum inter se bellum, si lumina uitae/ attigerint, quantas acies stragemque ciebunt.../ Ne, pueri, ne tanta animis adsuescite bella/ neu patriae ualidas in uiscera uertite uires:/tuque prior, tu parce, genus qui ducis Olympo,/ proice tela manu, sanguis meus! (VI 832-35) recuerdan los empleados por Lucano en esta ocasión, pero la contradicción entre la petición de Anquises a César y la realidad de los hechos subraya el carácter irónico de la evocación del modelo (E. Narducci 1976, p. 104). El uso reiterado de uiscera referido a lo más escogido del ejército pompeyano identificado con Roma (vv. 491, 500, 579, 722) atestigua la alusión y su sentido.

27 P. Esposito 1987, p. 73, apunta a Verg., Aen. IX 717-19.

EMERITA (EM) LXXIV 2, julio-diciembre $2006 \quad$ pp. 259-288 ISSN 0013-6662 
sencia de Belona en medio de la batalla de Farsalia (Quam cum sanguineo sequitur Bellona flagello, VII 568), que evoca la presencia de esta diosa de la guerra en la Eneida (Sanguineum ueluti quatiens Bellona flagellum, VIII 703 $)^{28}$, donde se la describe unida a Mauors. Pero a su vez la presencia de Palas en la narración lucánea, remite a través de una compleja red de alusiones (entre ellas Aen. VIII 433-8, donde Virgilio reúne a Marte y Palas describiéndolos con sus atributos bélicos característicos) ${ }^{29}$ a la teomaquia entre Marte y la portadora de la égida (cf. Hom., Il. XXI 391 ss.), enfrentamiento del que siempre sale victoriosa Palas, encarnación del orden, sobre Marte, símbolo del furor ${ }^{30}$.

La alteración integral del sistema ordenado de victoria/derrota elaborado por la tradición se completa con el recurso a un episodio mítico, el de la Gigantomaquia, que encuentra entre los augústeos, en especial en la Eneida ${ }^{31}$, un tratamiento privilegiado como instrumento para representar el triunfo del orden (y asimismo el de Octaviano) sobre el caos. Su inclusión en el momento de la descripción de la preparación de las armas, mediante la comparación explícita de la actitud del bando pompeyano con la que mostraron los olímpi-

28 Séneca (Dial. 4.35.6) introduce un verso muy semejante: sanguineum quatiens dextra Bellona flagellum, al que añade el anterior de Virgilio (Aen. VIII 702): et scissa gaudens uadit Discordia palla. Sobre este particular, véase E. Fraenkel 1970 [1924-25], pp. 25-6, P. Esposito 1987, pp. 78-83, y E. Narducci 2002, pp. 221-2.

29 Hemos simplificado en este punto la detallada explicación de P. Esposito (1987, pp. 76-83) en cuya conclusión indica que, siguiendo la tradición homérica de utilizar al dios de la guerra como figura simbólica con la que comparar a distintos personajes, Lucano lo asimila a César, a quien inviste de los valores simbólicos de Marte. Las relaciones intertextuales señaladas sirven para definir el carácter de César, pero creemos que la evocación de Turno lo incluye entre los vencidos, situación que en esta batalla no se produce.

30 La ira es, precisamente, una de las características más reiteradas del César de Lucano, rasgo que comparte con Aquiles y Turno (E. Narducci 1979, p. 96 ss., y 2002, p. 312). Una prueba más de la inversión de las expectativas de victoria y derrota en la Farsalia se encuentra en la ineficacia de la Górgona en el pecho de Palas para sembrar el terror ante Marte, trasunto de César, como señala M. Malamud 2003, p. 38.

31 También Horacio, Od. III.1.7 y Propercio IV 6 recurren a una simbología similar; cf. Ph. Hardie 1986, pp. 97-119. Dicho autor realiza en esta obra un importante análisis de la presencia y el significado del citado mito en la Eneida y la influencia en sus sucesores. Para D. Feeney (1991, pp. 296-7), la impiedad de la guerra civil permite su representación bajo al forma de la Gigantomaquia; en este caso una muy particular y extraña pues los Gigantes vencen. Según E. Narducci (2002, p. 309), su empleo subraya la dimensión universal del conflicto, pero también responde a los augústeos, cuyo empleo tenía por finalidad afirmar el triunfo del orden sobre el caos, con clara referencia al régimen de Augusto. En la misma línea de significación se encuentra la oposición entre Minerva y Marte.

EMERITA (EM) LXXIV 2, julio-diciembre $2006 \quad$ pp. 259-288 ISSN 0013-6662 
cos ante aquel acontecimiento decisivo: Si liceat superis hominum conferre labores, / non aliter Phlegra rabidos tollente gigantas/ Martius incaluit Siculis incudibus ensis/ et... (Luc. VII 144-50) ${ }^{32}$, establece una equivalencia incontestable: la identificación del bando cesariano con el de los Gigantes ${ }^{33}$. por lo que una vez más observamos la inadecuación de los modelos empleados respecto a la condición de vencedores y vencidos; lo que evidencia la distancia entre aquel suceso mítico que finalizó con el triunfo sobre el caos y la barbarie y éste que culminará con la derrota del orden. Por otro lado, esta acción, que, en principio, parece un signo de impiedad del bando republicano, adquiere, mediante la comparación con la acción de los dioses, una dimensión distinta, que justifica dicho acto en virtud de la trascendencia de la lucha ${ }^{34}$. El uso antifrástico del mito saca a la luz las contradicciones de la interpretación justificadora de la instauración del régimen imperial, e implica una relectura de dicho mito, una reinterpretación del significado de Accio $^{35}$.

La conclusión de este examen parece por lo tanto obvia, todo apunta a una búsqueda sistemática de modelos inadecuados en lo referente a la condición de vencedor y vencido con el fin de cuestionar la validez de las explicaciones que forjó la ideología imperial, y de negar la equivalencia de justicia y victoria; la elección de tales intertextos "inapropiados" forma parte del proyecto subversivo de Lucano, para quien sólo resta la consumación de la

32 Su intertexto más inmediato es la preparación de las armas por parte de los pueblos de Italia en Aen., VII 626-36, pero la comparación expresa de Lucano, remite al universo simbólico citado.

33 La equivalencia se hace explícita mediante la aplicación del término rabidos a los Gigantes 145 y rabies para definir la actitud de César y los suyos (vv. 551, 557). Los Galos, por otra parte, son un símbolo en la Eneida de los Gigantes según la interpretación de Ph. Hardie (1986, pp.123-5) y Lucano se refiere al ejército de César con el término Gallica rabies (eco de Livio XXXVIII 17 pues sólo ambos emplean dicha expresión). Por otro lado, confirma esta identificación, la interpretación del catálogo de tropas cesarianas que hace E. Batinski (1992). La autora citada lo considera como una inversión de dicha escena típica, pues Lucano subraya la felicidad que sienten los galos liberados de la presión del ejército cesariano. La finalidad de esta alteración es magnificar la fiereza de los soldados de César por encima de la proverbial de los Galos.

34 Cf. F. Schlonski 1995, p. 131.

35 Cf. M. P. O. Morford 1967, p. 55. La presencia considerable de este mito en la Farsalia (I 34-6, III 315-20, VI 347-8, 389-90, 410-2) responde a esa estrategia. D. Feeney 1991, p. 295, concreta el significado con estas palabras: «An indispensable part of the system is the quasidivine status of the tyrant. The gods favour Caesar because he is going to be one of them».

EMERITA (EM) LXXIV 2, julio-diciembre $2006 \quad$ pp. 259-288 ISSN 0013-6662 
destrucción de Roma.

\section{El intertexto historiográfico}

La incorporación de textos históricos complementa los modelos inapropiados de la épica con el paradigma historiográfico de narración de derrotas, que le sirve para poner en evidencia la distancia entre lo sucedido en Farsalia y la secuencia habitual que conduce al desastre del ejército romano.

Lucano acomoda la batalla culminante de su obra al diseño de las grandes derrotas romanas, pero lo hace introduciendo pequeñas alteraciones sobre el modelo básico de dicha macro-estructura. La evocación del mencionado paradigma y las sutiles variaciones que sobre él establece conceden a dicha batalla una fisonomía particular y conducen al lector a la conclusión de que esta derrota no encuentra explicación según los esquemas tradicionales, sólo se justifica aceptando su completa inversión. Es más, convierten la narración en una reflexión sobre los principios en los que se sustenta la mentalidad tradicional representada por la aristocracia romana, el sistema de valores aceptable para esta elite social: se enfrentan en el campo de batalla la ideología del pasado, sin vigencia en el mundo del poeta, y la del futuro, el presente de la época del poeta.

La obra de Livio es el espacio donde se plasman con mayor claridad y frecuencia estos paradigmas elaborados por la tradición que conforman, en conjunto, lo que podemos denominar un intertexto cultural (A. Barchiesi 1984 , p. 90 ${ }^{36}$. La presencia de Livio, difusa en ocasiones, concreta en otras, se encuentra en la base de la narración; y se hace patente mediante la evocación directa o la alusión. El modelo básico es el de la sucesión de derrotas encadenadas que sufre el ejército romano en sus primeros enfrentamientos con Aníbal, el enemigo de Roma por antonomasia y prefiguración del personaje de César ${ }^{37}$. Todos estos relatos responden a una estructura básica común. Si la elite romana, como ha demostrado N. Rosenstein (1990), ha pro-

36 Para más detalles, se puede consultar J. Bartolomé 2005.

37 Además de la dependencia del relato concreto de esta parte de la batalla, sólo reconstruible a partir de la tradición histórica dependiente del paduano, bien analizada por J. Radicke (2004, pp. 9-43). Podemos valorar las referencias concretas o la utilización de un léxico común, como prueba de esta traslación; así por ejemplo, el espectáculo de Cannas (Liv. XXII 51.5), los discursos previos al desastre en el Tesino, la identificación entre ambos personajes corroborada por la expresión cupido regni que aplica Livio a Aníbal en un discurso de Hannón (Liv. XXI 10.4) y Lucano a César (Luc. VII 240).

EMERITA (EM) LXXIV 2, julio-diciembre $2006 \quad$ pp. 259-288 ISSN 0013-6662 
curado salvaguardar sus privilegios ante la eventualidad de una derrota mediante un conjunto de justificaciones (la ruptura de la pax deorum, o la falta de virtud de los soldados), ${ }^{38}$ los historiadores elaboran un elenco más amplio de excusas o justificaciones (el desprecio de las advertencias divinas evidenciadas gracias a la presencia de prodigios de diversa índole; la negligencia, o la discordia entre los generales al mando de los ejércitos, o bien trampa del enemigo, compensación de la derrota, normalmente hecha explícita por parte del escritor), y consolidan con ello modelos narrativos. Esta forma de relatar pretende paliar las consecuencias de la aceptación de la equivalencia entre victoria y razón o justicia. El período de las Guerras Púnicas y en especial la Segunda, ${ }^{39}$ idealizado por la historiografía tardo-republicana, es ocasión propicia, por los importantes reveses militares sufridos antes de la victoria definitiva, para recordar que en ella se dilucida el castigo del culpable de la ruptura de los pactos y con ello de la profanación de los dioses en los que se sustentan. ${ }^{40}$ La presencia del hipotexto de la tercera década de Livio se hace aún más plausible por la aproximación a esta unidad narrativa del paduano detectable en el comienzo de la obra, que posee un parecido perceptible con el comienzo del libro XXI de Livio (J. Radicke 2004 , p. 160), por lo que no nos parece en absoluto arbitrario observar la confección de la batalla por parte del poeta a la luz de las prácticas del historiador.

Es en la fase de los preparativos -en la batalla no hace sino consumarse el trágico final que se adivina-, donde se disponen los signos anunciadores del desenlace, donde se presentan los factores determinantes del resultado; entre ellos cabe destacar debido a su importancia para nuestra demostración, por un lado, los dioses y, por otro, la uirtus y el ánimo de los soldados junto con la estrategia diseñada por el general ${ }^{41}$. Se trata, en apariencia, de una inversión del relato clásico de victorias; sin embargo, la conjunción de los factores señalados complica un esquema tan simple y determina la constitución

38 M. Rambaud 1980 y, más recientemente, B. Mineo 1997.

39 Es el modelo por antonomasia de guerra contra el enemigo externo y la derrota de Cannas constituye su momento de más alta dramaticidad, señala M. Fucecchi (1999, p. 323).

40 Livio entiende la victoria como justicia divina en el inicio de la Segunda Guerra Púnica: uicerunt ergo di hominesque et, id de quo uerbis ambigebatur uter populus foedus rupisset, euentus belli uelut aequus iudex, unde ius stabat, ei uictoriam dedit. (Liv. XXI 10.9) son palabras de Hannón referidas a la guerra anterior que recuerdan las de César, pero cuya formulación se contrapone a ellas y se aproxima a las dichas por Pompeyo (Luc. VII 22-3).

41 Cf. J. E. Lendon 1999, pp. 316-7.

EMERITA (EM) LXXIV 2, julio-diciembre $2006 \quad$ pp. 259-288 ISSN 0013-6662 
de un tipo de relato particular, el patético.

\section{Pompeyo arrastrado a la batalla}

La batalla está precedida por una escena en que presenta la situación en el campamento pompeyano, donde los subordinados reclaman al general la lucha (primero los romanos, a continuación los extranjeros), después de la intervención de Cicerón en favor de plantar batalla a César ${ }^{42}$. La inclusión de dicha escena es de una importancia extraordinaria. En primer lugar, porque le sirve para caracterizar a Pompeyo como un personaje dual dotado ahora, en su condición anticipada de vencido, de una clarividencia especial (Quis furor, o caeci...VII 95) ${ }^{43}$; asimismo el discurso de Cicerón, al que responde el de Pompeyo, sirve para anticipar el debate de cuestiones cruciales que se desarrollarán en las arengas (sobre todo la referencia a la confianza en los dioses: de superis, ingrate, times causamque senatus/credere dis dubitas? (76-7) ${ }^{44}$. En segundo lugar, porque reproduce aquí Lucano un paradigma de Livio: la discordia entre el general prudente y sus subordinados, ansiosos de lucha; la insistencia de Cicerón en plantar batalla y la amenaza de desobediencia al general no admiten discusión. De acuerdo con M. Leigh 1997, pp. 115-6, remite a la actuación de Camilo en Sátrico (Liv. VI 23-24), pero es fácil añadir otros más próximos, como las disensiones entre los dos cónsules de aquel año, Varrón y Paulo, que preceden a la batalla de Cannas ${ }^{45}$; la pre-sencia continua de este hipotexto a lo largo del relato, de forma directa o indirecta (mención comparativa, referencia expresa al comportamiento con los cadáveres de los combatientes caídos, estructura), lo corrobora: en primer lugar, se presenta la reclamación de los soldados: et clamore

42 Le proporciona una importancia mayor el hecho de tratarse de un suceso inventado por Lucano, ya que Cicerón no participó en esta batalla, cf. E. Malcovati 1953 y R. C. Lounsbury 1976. Remitimos igualmente al análisis de F. Schlonski 1995, pp. 117-21. No se puede excluir tampoco entre las causas de la introducción de esta escena la preocupación arquitectónica, como propone Radcike (2004, p. 380), pues responde al discurso de Curio a César. Interesante es la interpretación de Ch. de Nadaï (2000, pp. 238-42).

43 El intertexto (Verg., Aen. V 670) proporciona a Pompeyo una capacidad de ver con nitidez la catástrofe que se avecina superior a la del resto. En la formulación final de su discurso (omne malum uicti... omne nefas uictoris erit, Luc. VII 122-3), muestra sin paliativos lo trágico de su situación sin salida (F. Schlonski 1995, p. 126).

44 Tanto Cicerón como Pompeyo defienden sus posiciones desde una concepción tradicional.

45 Por supuesto, en la relación de Pompeyo con la demora frente a la rapidez de César subyace la oposición Fabio Máximo -Aníbal, cf J. Masters 1992, p. 1, n.1.

EMERITA (EM) LXXIV 2, julio-diciembre $2006 \quad$ pp. 259-288 ISSN 0013-6662 
orto a militibus, ni signum detur, sine ducibus ituros; haudquaquam dux defuit; nam extemplo Varro signum dedit proficiscendi (XXII 42.7); sigue, a continuación, la exposición de una serie de prodigios no atendidos (42.8-9); por último, en el momento de iniciarse la lucha, el historiador libera a Paulo de toda responsabilidad: ille, si quid proiectis ac proditis ad inconsultam atque inprouidam pugnam legionibus accideret, se omnis culpae exsortem... 44.7) y lo describe arrastrado a ella (sequente Paulo, 45.6) ${ }^{46}$.

Esta escena debe entenderse como signo anticipatorio de la derrota por identificación con los relatos de este tipo; pero induce asimismo a la comparación de los hechos con las expectativas creadas de acuerdo con los modelos a los que remite. La conclusión más sencilla es aceptar la pretensión de exculpar a Magno; otras, menos favorables al personaje, conducen a considerar que la muerte en combate (al igual que Paulo) - o su sacrificio (deuotio) como quiere M. Leigh (1997, p. 157) -, esperada de acuerdo con los modelos invocados, deja abierto el terreno a la ambigüedad en la valoración de la actitud de Pompeyo, pues, según su afirmación, «la Farsalia es un poema demasiado escéptico para entregarse la celebración acrítica o la exculpación de nadie, menos aún de Pompeyo». La comparación con Varrón, que proponemos nosotros, tampoco está exenta de ambigüedad pues es susceptible de interpretarse como una muestra de desesperanza por comparación con los personajes de los tiempos gloriosos del pasado ${ }^{47}$. En ningún caso se resuelve por completo, si bien la narración de la huida de Pompeyo al final de la batalla matiza las posibilidades.

\section{Los prodigios}

La enumeración de los prodigios anunciadores de la desgracia, siempre numerosos en caso de enfrentamiento civil $^{48}$, responde a la misma lógica que el resto de preparativos. Como es natural, Lucano los sitúa en el inicio de la guerra (I 523-695) y de la batalla decisiva (VII 185-204), pero nos inte-

46 Como prueba indirecta se puede aducir la utilización de la batalla de Farsalia para el relato de la batalla de Cannas por parte de Silio Itálico IX 211, X 450 y ss. (M. Fucecchi 1990, 1999). La construcción del Varrón, empeorado, sobre la base del Cicerón de Lucano en Punica, de acuerdo con M. Fucecchi (1999, p. 327), constituye una prueba de lo que decimos.

47 Valoración que coincide con la de de Catón en su laudatio funebris de Pompeyo (Luc. IX 190-214).

${ }_{48}$ Cf. P. Jal 1963, pp. 238-9.

EMERITA (EM) LXXIV 2, julio-diciembre $2006 \quad$ pp. 259-288 ISSN 0013-6662 
resan aquí concretamente los que preceden de forma inmediata a la lucha y se producen, de forma exclusiva, en el campamento vencido (vv. 150-67) ${ }^{49}$. Los prodigios se entienden como manifestación de la ira de los dioses, y, por ello, pocas veces faltan en las derrotas romanas, de las que a menudo son una justificación ${ }^{50}$. La función de la presencia de lo divino en la tercera década de Livio es, según las palabras de D. S. Levene (1993, p. 77): «reforzar la idea de que la piedad es recompensada, y la impiedad castigada, y de forma más general, que la victoria romana ha sido garantizada por los dioses. Esta idea sólo aflora a la superficie en contadas ocasiones, pero se halla presente en la mayor parte de su narración ${ }^{51}$. Asimismo los dioses de la Eneida apoyan al pius y castigan al impius ${ }^{52}$. Si intentamos aplicar este principio al pasaje de Lucano, observamos que ha dejado de funcionar. No se puede hablar de falta alguna, ni, como es el caso de Flaminio en el Trasimeno (XXII 3.12), de una desatención hacia los prodigios ${ }^{53}$, tampoco de un advertencia divina que exija el cumplimiento de las condiciones necesarias para aplacar a los dioses en el momento en que estos se muestren dispuestos a ello (así en el Tesino o en Cannas); la imposibilidad de alcanzar el favor divino, es el resultado del destino trágico de Roma que los dioses, aunque

49 Los refieren también Dión (XLI 61.2), Valerio Máximo (I 6.12), Floro (Epit. II 13.45), Apiano (BC II 68), donde se habla de anuncio de la victoria, Obsequens (65a). Pero existen diferencias, o se alude a los dos campamentos, o se habla de ambigüedad en la interpretación (Plutarco, Caes. 43.5, Apiano, BC II 68-9).

50 Se trata de un mecanismo habitual de exculpación (N. Rosenstein 1990, pp. 54-91). Su inclusión responde al deseo de reflejar la mentalidad de los protagonistas de la acción, no a la opinión de los historiadores, como pone de manifiesto E. Fantham (2003, pp. 243 y 247-8).

51 R. C. Lounsbury 1976, pp. 210-239, y F. Schlonski 1995, p. 116. La coincidencia con diversos pasajes de Livio (abejas: XXI 46.2, peso de los estandartes: XXII 3.11-12 y huida de la víctima sacrificial: XXI 63.13) en los que se anuncian prodigios en el contexto de derrotas da validez a nuestro argumento. Por otro lado, la utilización para el relato de Cannas por parte de Silio Itálico de algunos de los prodigios formulados por Lucano en este pasaje (VII 151 ss.) y por Livio en distintos lugares, como indica E. Ariemma (2000) en su comentario a los versos VIII 622-27 de Punica, confirma la práctica de Lucano a la hora de servirse del paduano como intertexto y el significado de esa utilización.

52 P. Esposito 1987, p. 115, proporciona interesantes datos sobre el uso de estos términos.

53 Esto, señala M. Fucecchi 1999, p. 329, lo distingue del Varrón de Punica, que, ciego frente a los signos inequívocos enviados por los dioses, avala con su comportamiento el designio del destino. Apiano ( $B C$ II 68-9) por su parte, advierte cierta ligereza en la actitud ante los anuncios.

EMERITA (EM) LXXIV 2, julio-diciembre 2006 pp. 259-288 ISSN 0013-6662 
no intervengan en la acción, consienten ${ }^{54}$, como reitera desde el inicio Lucano (I 128), y del apoyo a su causa de potencias oscuras como los dioses infernales (vv. 169-71). No se explica, por tanto, el desenlace favorable de la lucha como fruto de la piedad de César, por pasajera que fuera, tampoco por culpa o impiedad del Pompeyo ${ }^{55}$.

\section{La formación de los ejércitos}

En la descripción de la preparación de la batalla, sorprende que el narrador describa la disposición táctica de la acies pompeyana (vv. 214-34), con diferencias de detalle respecto a otros autores, y, en cambio, no mencione la formación del ejército cesariano, al contrario, señala de modo expreso su falta de orden: stant ordine nullo/ arte ducis nulla (vv. 332-3) ${ }^{56}$, en oposición a las bien organizadas filas de Pompeyo: Non temere inmissus campis: stetit ordine certo/ infelix acies (vv. 216-17) ${ }^{57}$. El paralelismo léxico y la idéntica situación en el verso acentúan el contraste. Este hecho posee importancia pues, precisamente, la falta de orden y la precipitación es, por un lado, uno de los tópicos justificativos de las derrotas romanas ${ }^{58}$, por otro, una característica de la forma de actuación de pueblos bárbaros frente a la disciplina romana ${ }^{59}$. Dicho extremo constituye una pieza más en la estrategia de expresar la contradicción de las expectativas y el desenlace de la batalla ${ }^{60}$. La

54 C. Codoñer 2003, pp. 305-15, resume de forma espléndida esta cuestión. Cf. asimismo J. M. Núñez 2002.

55 Así lo hace Livio con los éxitos pasajeros de Aníbal, que los asocia a su reciente piedad, como indica D. S. Levene (1993, pp. 45-6) en referencia a XXI 22.6-9.

56 M. Lausberg 1985, p. 1569, encuentra un antecedente en el relato de la disposición de troyanos y griegos en Homero (Il. III 2-8), sin embargo creemos que el simbolismo lo aproxima más a este otro eje valorativo; por otro lado, la expresión ordine nullo, de cuño cesariano (Gall. I 51.2, II 11.1; Ciu. II 26.4) favorece nuestra interpretación.

57 Cf. E. Narducci 2002, p. 218. La expresión temere, aquí negada, es clave en la definición de la mala actuación de los generales romanos en la obra de Livio.

58 Heródoto (VIII 86) ilustra de modo ejemplar la importancia del orden de batalla en su explicación del resultado de Salamina; la enunciación teórica del principio le corresponde a Vegecio (Epit. III 20.20). Como ejemplos de las consecuencias del desorden de un ejército, los más significativos en Livio son la batalla del Alia (Liv. V 38) y la de Herdónea (Liv. XXV 21.5-6), que posee, además, otras semejanzas con el relato de Lucano, como son la desesperación y el hecho de que el general se deja arrastrar a la batalla.

59 Furor y rabies contribuyen a la identificación entre los rabidos gigantas (v. 145) y los cesarianos (E. Narducci 2002, p. 309).

60 P. Esposito 1987, p. 116 indica que el uso de scelus en 10 casos referido a César y sus soldados indica la parcialidad del relato, ocultando las causas estratégico-militares de la victo-

EMERITA (EM) LXXIV 2, julio-diciembre $2006 \quad$ pp. 259-288 ISSN 0013-6662 
validez de este argumento se deriva de dos circunstancias: en primer lugar, de la contradicción dentro de la narración pues Lucano, en el curso de la batalla recuerda la disposición de la quarta acies cesariana (vv. 521-4); en segundo lugar, se trata de una elaboración particular de Lucano pues contradice plenamente la realidad histórica de acuerdo con lo transmitido por otros autores ${ }^{61}$. Es más, como ha subrayado J. E. Lendon (1999, pp. 273-329), si César plantea los relatos de batalla basados en tres pilares (estrategia, animus y uirtus; precisamente los tres exigencias que cumple el bando pompeyano: vv. 216, 383) es esta batalla donde insiste de forma más clara en el carácter decisivo que tuvo la táctica.

De ello se deduce que Lucano ha querido destacar el carácter bárbaro de la actuación de los cesarianos, su brutalidad, el ansia por llegar a la victoria frente a las reticencias continuas de Pompeyo, y del propio narrador, envarado siempre en la demora y el deseo de evitar el final de la guerra de consecuencias indeseadas (I 672), pero también pretende confrontar el resultado con la lógica de la victoria, acentuando la falta de razón de su triunfo incluso en el plano militar ${ }^{62}$.

Otra consecuencia que se desprende del cambio introducido por Lucano es su rechazo a otorgar al texto cesariano la condición de acceso privilegiado, incluso de acceso aceptable, para la reconstrucción de los sucesos por ambos narrados ${ }^{63}$.

\section{Las arengas}

Por último, la presentación y el contenido de las arengas determinan la superioridad del bando vencido. Entre los factores de mayor valor figuran el orden y los gestos ${ }^{64}$, la actitud de oradores y auditorio, y las referencias intertextuales. La conjunción de todos ellos dirige la recepción del lector de un modo particular.

ria.

61 César, Ciu. III 88-9, Apiano, BC II 75-76, Plutarco, Caes 44.y Pomp. 69.

62 E. Narducci 2002, p. 217 ss.

63 No creemos sin embargo que Lucano haya pretendido contradecir de forma sistemática la obra de César, como defienden M. Rambaud (1960) y J. Henderson (1988, pp. 133, y 1998), entre otros.

64 Sobre la importancia de estos factores, el estudio de A. Laird (1998, pp. 121-6) resulta de utilidad. Podríamos añadir asimismo la extensión del discurso, bastante menor en el de Pompeyo, lo que constituye un indicio de la contención, moderación y asimismo de su predisposición anímica.

EMERITA (EM) LXXIV 2, julio-diciembre $2006 \quad$ pp. 259-288 ISSN 0013-6662 
Cuando se incluyen en las obras históricas los discursos de dos personajes enfrentados, suele hablar en último lugar el vencedor en la disputa, algo semejante ocurre en las contiendas verbales representadas en la épica ${ }^{65}$. Sin que constituya una norma en el caso de las arengas, se observa, al menos en Livio, la tendencia a colocar el discurso del general cuyo ejército resulta vencedor en último lugar, con lo que se le concede así la oportunidad, que no tiene el primero, de contestar los argumentos de su oponente, probando ante el lector la supremacía de su causa. Facilita esta interpretación la semejanza de los argumentos empleados por uno y otro, lo que conforma el segundo discurso como una respuesta al primero ${ }^{66}$. La concordancia de las palabras expuestas por Pompeyo (se hace eco de los mismos presupuestos, como se desprende de la repetición léxica de la narración y de los discursos, del mismo modo el desacuerdo con César al que desmiente sin contemplaciones, respeta la realidad narrada a diferencia de su oponente, que la falsea) con lo narrado y con las intervenciones directas del narrador conceden crédito a los argumentos del Magno y pretenden demostrar, pues se le concede el privilegio de decir la última palabra, la superioridad de su causa y, con ello, la victoria moral del bando pompeyano, indicio frecuente de victoria real.

Las arengas se encuentran precedidas por la caracterización de los oradores (vv. 248-9 y 341-2, respectivamente) y se cierran con la reacción del auditorio (vv. 329-31 y 382-4, respectivamente). La disposición mental de ambos, definida por el temor, evidencia la transformación necesaria en la actuación pública que tiene por objeto el enardecimiento de los oyentes. La reacción de los soldados demuestra el poder de convicción de ambos, el éxito, por vías distintas, de su retórica. Antes de ocuparnos de la articulación de esa retórica, basta con señalar que la forma de resolver el sentimiento inicial común (vv. 248-9 y 340-2, respectivamente) y, más aún, la reacción, tan diferente, del público de cada uno, insisten en poner de manifiesto la superio-

65 Así ocurre en la batalla del Tesino (Polibio III 64, en cambio, altera el orden), en la segunda batalla del Alia (VI 28-29); en este caso bajo la forma de pensamientos recogidos en estilo indirecto, y en Zama. Una prueba indirecta de los que decimos está en el hecho de que Apiano recoge los discursos en el orden contrario ( $B C$ II 72 y 74, respectivamente), pese a que en ambos casos poseen un fondo común y parecen responderse el uno al otro. La misma interpretación da W. D. Lebek (1976, p. 235, n. 7) a la alteración del orden propio de la épica en las palabras que César y Domicio intercambian en el combate que conduce a la muerte de este último.

66 Coincidimos en esto con el análisis de G. H. Goebel (1981, p. 82).

EMERITA (EM) LXXIV 2, julio-diciembre $2006 \quad$ pp. 259-288 ISSN 0013-6662 
ridad de Pompeyo, simbolizada por la solemnidad que le concede su presentación externa (J. Radicke 2004, p. 402): a los soldados de César los impulsa a la lucha de forma precipitada la ira y la ambición suscitadas por el discurso de su general (Vix cuncta locuto Caesare quemque suum/ munus trahit armaque raptim sumpta/ Ceresque uiri, vv. 329-31); las motivaciones que impulsan a los pompeyanos responden a principios tales como la defensa de la libertad y la dignidad de su general, cuya actitud, lejos de la euforia, se resume en la expresión: tam maesta locuti uoce ducis flagrant animi Romanaque uirtus ${ }^{67}$ / erigitur placuitque mori, si uera timeret, vv. 382-84).

Si pasamos ahora a la articulación de las arengas, observamos que, si bien respetan las convenciones de la retórica militar, lo que les da un aire de familia, las diferencias, cruciales, refuerzan lo indicado por otros factores ${ }^{68}$.

Ambas tienen una misma finalidad: enardecer a los soldados ante el enfrentamiento que se avecina y para lograrlo buscan fortalecer su confianza ${ }^{69}$. El discurso de César intenta, por un lado, suscitar el sentimiento de alegría y satisfacción por el inicio de la lucha; por otro, prevenir los posibles peligros, mediante la insistencia en la debilidad del adversario y el valor propio (vv. 269-91). A continuación pretende provocar otros dos pathe, en este caso mediante el recurso a la representación plástica (euidentia): el sufrimiento posible ante la derrota y la indignación contra el enemigo por su futura crueldad (vv. 303-7). El último de los movimientos del discurso tiende a suscitar la idea de clemencia (vv. 320-1). César se presenta bajo la luz más favorable para lograr la convicción del auditorio: la de hombre benevolente, virtuoso, y, en menor grado, prudente. Su éxito no muestra otra cosa sino la coincidencia entre orador y público, pero ante el auditorio externo sus palabras delatan la falsedad de su discurso: los principios morales no son sino una justificación cínica de sus aspiraciones, y su petición de apoyo divino no se basa en la pietas. La arenga de César manifiesta la inversión perversa de la mentalidad tradicional, que considera que los dioses otorgan la victoria

67 Responde esta reacción al argumento exhibido por Pompeyo, que considera a su ejército investido de la uirtus de los tiempos gloriosos de Roma. Sobre el empleo del término uirtus en Farsalia y las complejidades del uso en este pasaje remitimos a R. Sklenár 2003, pp. 117-8.

68 G. H. Goebel 1981 analiza en detalle los tópicos en que se basan los discursos de ambos generales.

69 En este punto seguimos básicamente el análisis retórico de $\mathrm{Ch}$. de Nadaï 2000, pp. 222-38.

EMERITA (EM) LXXIV 2, julio-diciembre $2006 \quad$ pp. 259-288 ISSN 0013-6662 
a la causa justa ${ }^{70}$; para él, en cambio, la victoria es el árbitro de la razón y posee capacidad para limpiar la culpa: haec acies uictum factura nocentem est... gladio exoluite culpam:/nulla manus, belli mutato iudice, pura est (vv. 259-63) ${ }^{71}$. Aunque, en efecto, esta es la verdad que late en el fondo de la concepción romana, la expresión de César lo evidencia con todo el cinismo posible (Di... uincat qui..., vv. 310-1 ${ }^{72}$ ). Niega, además, la condición criminal de la lucha, reiteradamente señalada por el narrador, y manifiesta su impietas cuando insta a sus soldados a superar el temor que la presencia paterna en el otro bando impone, desmintiendo que combatirlos sea un acto criminal (non uos pietatis imago/ ulla nec aduersa conspecti fronte parentes/ commoueant: uoltus gladio turbate uerendos, vv. 320-2) ${ }^{73}$. La expresión pietatis imago, que encuentra su contrapunto en la veneración de los antepasados expresada en el discurso pompeyano: sponte uiri sacraque antiquus imagine miles (v. 357), opone las actitudes de ambos en detrimento de César ${ }^{74}$. Su imagen como orador remite a la del conspirador, del tirano o del enemigo lleno de soberbia pero destinado a la derrota (Catilina, Alejandro

70 La lógica perversa de estos planteamientos quedan patentes en las palabras de A. Feldherr 1998, p. 55: «Cada tratado internacional impone una obligación religiosa a sus firmantes, y los dioses que sirvieron como testigos de un tratado eran frecuentemente invocados para castigar a su violador. Puesto que estas fuerzas no podrían cooperar con aquellos cuyas reclamaciones eran falsas, cada demostración de superioridad militar necesariamente establecía la versión de los sucesos del bando vencedor».

71 Merece la pena reproducir las palabras de O. Due 1962, p. 116, en su comentario a este pasaje: «César en diversas ocasiones en sus discursos mantiene que el resultado de la guerra decidirá la cuestión de la culpa $(1.227,7.259)$, y el resultado [...] permite a su victoria convertirse en oficialmente justa, y garantiza a César el derecho de colocar la culpa en el bando derrotado y esclavizar a Roma». De acuerdo con E. Narducci 1976, pp. 127-8, se desvela la ley del más fuerte, la razón es la fuerza: «El termino iudex se refiere tanto al vencedor de la guerra civil como a los dioses que lo protegen; la bestial crueldad de César se identifica con la voluntad de estos. Estamos ahora en disposición de captar en toda su fuerza titánica contestataria el celebérrimo uictrix causa deis placuit sed uicta Catoni». La comparación con las palabras de Pompeyo: omne malum uicti... omne nefas uictoris erit (120-3) acentúa la perversidad del razonamiento cesariano.

72 Cf. G. H. Goebel 1981, pp. 85-86. Al mismo principio de legitimidad recurren en sus discursos antes de Zama Aníbal y Escipión (Liv. XXX 31.5 y XXX 31.10, respectivamente).

73 Lucano, además, tergiversa una de las órdenes de César, que Floro (Epit. II 13.140) recoge: parce ciuibus; en cambio, ambos coinciden en la orden de herir en el rostro, algo de lo que se hacen eco igualmente Plutarco (Caes. 45.2) y Apiano (BC II 78).

74 La expresión, virgiliana (Aen. VI 405, IX 294, X 824), contribuye a dibujar el vuelco completo del universo de los valores romanos.

EMERITA (EM) LXXIV 2, julio-diciembre $2006 \quad$ pp. 259-288 ISSN 0013-6662 
Magno, Aníbal), sólo que en este caso ese final esperado no se da ${ }^{75}$.

Consigue Pompeyo infundir confianza en sus soldados de modo muy distinto. En primer lugar desarrolla, bajo la forma de un silogismo, el principio de que los dioses deben apoyar la causa propia (la libertas actual y la del futuro) por ser la mejor (causa iubet melior superos sperare secundos, v. $349)^{76}$; a continuación aduce como indicio del apoyo divino su propia vejez (vv. 353-5). Añade como argumentos la valía de sus tropas, y para ello se basa en el número y, sobre todo, en la nobleza de sus ejércitos (vv. 355-68), estableciendo así una extensión de los efectivos, por un lado, temporal: es la tradición de Roma republicana lo que se juega en la batalla; y, por otro, espacial: el mundo entero se encuentra involucrado en la lucha (v. 363 ${ }^{77}$. Suma a este sentimiento el de la amicitia y el de la pietas hacia la patria ${ }^{78}$; la imagen de la patria que recrea mediante el recurso a la euidentia completa su discurso apelando a los sentimientos más eficaces y nobles de sus soldados.

La seguridad de César, evidenciada en el uso abundante del imperativo ${ }^{79}$, contrasta con el estilo de Pompeyo, que recurre en puntos decisivos a las condicionales o interrogativas para dar credibilidad a sus argumentos. Pero la decantación del valor de las arengas se confía a medios, como la coincidencia con la expresión del poeta, que interviene directamente, y con ello subraya que en este caso la razón se halla en el bando vencido, sólo que ya los dioses no defienden la justicia ${ }^{80}$. Lucano pone al descubierto la falsedad

75 Cf. E. Narducci 1976, p. 101 ss.

76 Lo categórico de la declaración, como señala W. Tasler 1972, p. 112, contrasta con el miedo que delata en la contradicción de iubet sperare. La mentalidad según la que razona Pompeyo se corresponde con la de los personajes históricos de Livio; véase, por ej., la arenga del cónsul L. Papirio antes de la batalla de Aquilonia contra los Samnitas (X 39.14-15).

77 Opinión diferente sostiene G. H. Goebel 1981, pp. 88-9, que indica el mal empleo del tópico de la comparatio uirium por parte de Pompeyo. Coincidimos con él en que se trata de un argumento débil, y donde demuestra el Magno una seguridad inesperada, pero se advierte que en el discurso se antepone a otra intención el deseo de responder al locus de barbaris esgrimido por César contra el ejército pompeyano. Además la dimensión universal del conflicto es un tema reiterado en la obra de Lucano, como hemos dejado señalado en la nota 11.

78 La imagen de la patria (Virgilio, Aen. XII 132-33 y VIII 592) recuerda también la reacción romana ante la amenaza de Aníbal. Cf. P. Jal 1963, p. 342, sobre espectáculo y guerra civil.

79 Son aplicables a este discurso las conclusiones de M. Helzle 1994 sobre el carácter de la retórica de César: utiliza siempre el registro militar, imperativos y vocabulario violento.

80 Cf. D. Feeney 1991, pp. 278-85.

EMERITA (EM) LXXIV 2, julio-diciembre $2006 \quad$ pp. 259-288 ISSN 0013-6662 
e hipocresía de las palabras de César, mediante la contradicción de éstas con el relato proporcionado por el narrador (con respecto al comportamiento de Pompeyo en Dirraquio, vv. 315-8, y lo que señala el poeta en el momento de su narración, VI 303), así como con la negación de uno de los postulados básicos, reiterado y persistente a lo largo de la obra, de la Farsalia: la guerra civil es un nefas (non credit fecisse nefas, v. 315) que convierte en culpables a sus participantes ${ }^{81}$. Las contradicciones internas desvelan asimismo el carácter falaz de los argumentos de César: habla del interés por sus soldados, no de Roma como Pompeyo, pero, aún así, desvela su interés personal, habla de libertas, pero sólo para los suyos, de clemencia y se muestra cruel (W. Tasler 1972, pp. 66-67), y pese a todo ello será el vencedor.

La excelencia de los argumentos de Pompeyo delata la contradicción entre razón y resultado. El poeta ha pretendido, al conceder la palabra a César, mostrar los motivos profundos de su actuación y subrayar que recibe el apoyo divino pese a la falta de legitimidad de su causa. Con el fin de hacerlo más evidente plantea el discurso de Pompeyo como una reflexión sobre la legitimidad y la justicia divina.

A lo dicho se debe añadir un dato más que instala la arenga en el marco del esquema de derrotas. El discurso de César encuentra paralelos notables en la arenga de Aníbal que precede al primer enfrentamiento con los romanos en Italia, el del Tesino. Llama la atención, además de los numerosos ecos verbales (J. Lorenzo 1991), la coincidencia en el uso de algunos argumentos. En efecto, la idea de la crueldad del enemigo, del perdón de consecuencias nefastas, la invocación a los dioses como garantía de su acción. Menos perceptibles, pero aceptables son las correspondencias entre la arenga de Pompeyo y la de Escipión en esa misma batalla (XXI 41), especialmente cuando plantea la lucha como defensa de la patria asediada $(41.16)^{82}$. El corolario de la comparación, la identificación entre Aníbal y César, resulta problemático en algunos puntos, pues la figura del cartaginés no es unívoca: por un lado,

81 La oposición entre César y el narrador se acentúa si tenemos en cuenta que nefas es uno de los términos claves de definición de la guerra civil a lo largo de la Farsalia; igualmente se esfuerza por borrar la culpabilidad de su bando mientras que Lucano insiste en aplicarles el adjetivo nocens (empleado en 10 ocasiones en el libro VII, cf. P. Esposito, 1987, p. 105 ss.). Por otro lado, señala E. Fantham 2003, p. 247, el propio César reconoce la injusticia de lo sucedido (IX 1101-2), aunque transmita, de forma hipócrita, el pensamiento de Pompeyo.

82 G. H. Goebel 1981, p. 87, observa igualmente puntos de contacto entre las palabras de César y las de Aníbal (Liv. XXI 43.17).

EMERITA (EM) LXXIV 2, julio-diciembre $2006 \quad$ pp. 259-288 ISSN 0013-6662 
es el vencedor en esta batalla, pero, por otro, es un vencedor temporal destinado a la derrota definitiva, como lo expresa Livio en el momento mismo de sus mayores victorias (XXII 46, 8-9, 54 10-11) y se reitera en los discursos que anteceden a la victoria final romana, la de Zama (XXX 30-32); nada similar sucede en la Farsalia, pues, aunque se aceptasen las alusiones a la muerte de César como una forma de compensación a su éxito ${ }^{83}$, la consecuencia más grave de su victoria, la pérdida de la libertad, permanece presente en la generación de Lucano (prosternimur, v. 641). Así, la identificación en la actitud y el carácter de ambos personajes busca, una vez más, subrayar la frustración de las expectativas que supone el desenlace de esta batalla.

\section{El relato patético de la batalla}

El proceso iniciado en la preparación encuentra su culminación en el relato de la batalla misma, en el que se advierte la desfiguración, propia de las derrotas, del relato lógico, sólo que aquí se lleva a sus términos más extremos, sobrepasando a sus modelos. Con las premisas de las que parte Lucano no puede caer en la trampa de narrar la batalla al modo tradicional de la épica, como un espectáculo cruel pero glorioso; tampoco mediante la adecuación al relato racional clásico, que, por estructura, quita la razón al vencido, asimilando de manera automática del vencido con el culpable (VII 260) ${ }^{84}$, sino que debe servirse de una forma narrativa opuesta, que se concreta en lo que J. Kaempfer (1998, p. 122) denomina "relato patético", un tipo de relato que expone con detalle minucioso los aspectos más detestables de la guerra, e implica una nueva consideración de las víctimas. Los modelos narrativos de derrotas de la historiografía, que con frecuencia eluden o alteran el orden habitual ${ }^{85}$, le son útiles, pero no consiguen por completo dar cauce adecuado a la expresión que pretende, por lo que, partiendo de ellos, acentúa los ras-

83 Esta es la opinión de F. Ahl 1993, p. 125, a la que se opone, acertadamente según nuestra opinión, C. Codoñer 2003, p. 323. n. 46.

${ }^{84}$ «El relato patético - define J. Kaempfer 1998, p. 156 - ignora la clarividencia de la mirada estratégica; muestra la guerra de cerca, y reflexiona de lejos. Coloniza los márgenes del relato racional, y designa así los límites en los que éste se encierra - la demasiado cómoda ceguera en la que se funda».

${ }^{85}$ Algunas ideas sobre este particular se encuentran en J. Bartolomé 1995, pp. 42-5, y 1996. De acuerdo con P. Esposito 1987, pp. 68-9, lo que en los historiadores es manifestación de lo excesivo en las batallas se convierte aquí en el único modo de descripción bélica. Además, Lucano efectúa «un desmontaje completo del código de la épica» en este tipo de narraciones (Íd. 1987, p. 122).

EMERITA (EM) LXXIV 2, julio-diciembre 2006 pp. 259-288 ISSN 0013-6662 
gos más característicos en el contenido (la ausencia de batalla en Alia, la crudeza en el Trasimeno, la descripción del campo de batalla de Cannas cubierto de cadáveres ${ }^{86}$, y supera además, mediante las intervenciones en primera persona y la fusión del tiempo de lo narrado y el de la narración, la distancia (en gran medida atenuada gracias a técnicas como la selección del punto de vista fijo o del foco único), del historiador (P. Esposito 1978, p. 124). La elección del punto de vista del vencido determina el especial desarrollo de la narración de la batalla, expuesta como un espectáculo de horror que degrada al vencedor (M. Leigh 1997, p. 39).

La comparación más superficial del relato de los mismos acontecimientos en la obra de César (Ciu. III 82-94) y en la Farsalia pone de manifiesto una visión diametralmente opuesta; el trazado simétrico cesariano que justifica la victoria en la lógica de una buena planificación estratégica y la adecuada ejecución, se transforma en una narración en la que la proporción y lógica desaparecen, en la que la estrategia deja paso a la furia y las acciones militares ceden su puesto a la masacre. Lucano se limita a proporcionar el marco básico, que garantiza la claridad suficiente para la comprensión del sucederse de las acciones ${ }^{87}$, lo demás es un conjunto de escenas grotescas cuya narración compromete. Unas calas bastarán para ilustrar lo que decimos y poner fin a nuestro estudio.

La narración selecciona momentos de especial significado, cuyo valor acentúa la intervención del narrador. Así, antes del enfrentamiento crucial, el poeta expresa su negación a narrar las atrocidades de las que debe dar cuenta (el recurso a la inversión de uno de los módulos expresivos de la invocación a la Musa: fuge, mens: nullaque tantorum discat me uate malorum... quidquid in hac acie gessisti, Roma, tacebo, vv. 553-54, profundiza la ironía) ${ }^{88}$, y sustituye el relato propiamente bélico por una descripción de la minuciosidad con que César escruta las acciones de sus hombres (Inspicit et gladios, quil qui / quae... quis/ quis... quis/ quem... quis; [...] scit... qui sit,

86 Remitimos para más detalles a nuestro estudio (J. Bartolomé 2005) de próxima aparición.

87 La estructura que observa J. Radicke 2004, p. 404, es la siguiente: 1. Avance de los ejércitos y reflexión histórica (vv. 385-459), 2. Comienzo de la lucha (vv. 460-505), 3. Lucha en las alas (vv. 506-544), 4. Lucha principal (vv. 545-96), 5. Derrota pompeyana y reflexión histórica (vv. 597-646).

88 Se trata de una significativa praeteritio, como se desprende de los análisis de K. Ormand 1994, p. 53, y W. R. Johnson 1987, pp. 98-99.

EMERITA (EM) LXXIV 2, julio-diciembre $2006 \quad$ pp. 259-288 ISSN 0013-6662 
quae/ unde/ quo, vv. 557-65 y 579-83 ${ }^{89}$, pero, finalmente cede a la necesidad imperiosa de narrar, y cuando lo hace es para dar cuenta de la actuación de César bajo la forma de una aristía épica invertida, que la transforma en un espectáculo grotesco ${ }^{90}$, donde contienden personajes anónimos ante la omnipresencia brutal de César, un héroe presa del furor que irradia su rabies $^{91}$. La comparación de su actuación como un avance entre la catástrofe y la matanza (it uagus, v. 559, quacumque uagatur, v. 566) con la presencia de Marte y su séquito en la batalla, que ya hemos señalado, completa de forma inequívoca el significado de su caracterización ${ }^{92}$.

Un segundo momento importante es el de la enumeración de los combatientes muertos; nuevamente expresa, mediante la praeteritio, su rechazo a narrar, en esta ocasión a referir las muertes particulares (Inpendisse pudet... ac singulis fata sequentem/ quaerere, vv. 618-9); consigue así la inversión de una escena típica de la epopeya: el catálogo de muertos en combate ${ }^{93}$, recurriendo a un módulo estilístico semejante al anterior (per cuius uiscera uolnus/ exierit, quis/ ore quis/ quis/ quis...qui/ quos/ quis / quis/ quis, vv. 619-30); una marca sustancial de la inversión es la ausencia de nombres propios; los muertos son condenados al anonimato, el mejor premio en una guerra que no procura gloria alguna ${ }^{94}$.

El tercer momento es el de la descripción del campo de batalla, expuesta a través de la visión de César (vv. 789-803), que se deleita en el espectáculo.

89 La utilización en este pasaje del núcleo de la revista de los soldados (epipolesis) por parte de Agamenón (Hom., Il. IV 231 ss.) acentúa su carácter tiránico, cf. M. Lausberg 1985, p. 1577.

90 La ausencia de nombres propios es clave de la estrategia de subvertir la escena épica de la aristía, cf. B. Gormann 2001, esp. p. 270.

91 Algunos usos de la palabra rabies en Livio son de interés: XXV 37.11; XXIX 9.6; XXXII 23.9 y de forma especial XXXVIII 17.8, donde se opone la rabies gala a la uirtus romana (oposición que a distancia recoge Lucano, véase nota 30). Conviene recordar que la ira es uno de los ragos reiterados en la definición de César (E. Narducci 1979, p. 106 ss., y 2002, pp. 309-12).

92 La interpretación de la presencia de César en medio de la batalla es controvertida; para E. Narducci (2002, p. 221), responde a un tópico de las narraciones bélicas, que Lucano invierte en contra de César. P. Esposito (1987, p. 92), por su parte, la considera su actitud como la propia de un imperator que se rebaja a la categoría de miles, y es asimilado en este aspecto a personajes como Alejandro Magno y Catilina.

93 La comparación con el catálogo correspondiente de Virgilio (Aen. XII 500-4) muestra la distancia.

94 Se trata de una inversión del catálogo épico de muertos, cf. P. Mazzochini 2000.

EMERITA (EM) LXXIV 2, julio-diciembre $2006 \quad$ pp. 259-288 $\quad$ ISSN 0013-6662 
Nos encontramos ante una nueva inversión, ahora de una escena entre épica e histórica, con la misma finalidad de las anteriores ${ }^{95}$.

Por último, la escena de la huida de Pompeyo (vv. 647-727), su acción más difícil de justificar tanto según las exigencias del código social, del que se hace eco el género histórico, como desde el punto de vista del código heroico, se transforma respecto a su significado habitual y sólo encuentra justificación aparente como contrapunto a los efectos de la aristía: evitar un derramamiento de sangre mayor (671-2). Así parece confirmarlo el monólogo de Pompeyo y la voz autorial que acompaña su huida y aplaude su suerte por liberarse del espectáculo de sangre que deja a sus espaldas (vv. 685 ss.), aunque la formulación próxima a la de la deuotio (M. Leigh 1997, pp. 1527) mantiene la ambigüedad.

En conjunto, tal descripción de la batalla dramatiza el acto mismo de la contemplación del espectáculo, como propone M. Leigh (1997, p. 110 ss.), pues el relato de Lucano, reticente a mostrarlo pero obligado a ello, lo coloca ante los ojos del lector y fuerza su reacción. El texto manifiesta en distintas ocasiones la ecuación entre conocimiento visual y complicidad: los soldados, que se paralizan antes de la batalla, se llenan de culpa con su conocimiento (vv. 462-65); a César lo domina un deseo morboso de contemplación (vv. 292-4); Pompeyo, en cambio, imagina el espectáculo y lo lamenta (vv. 114-6); el poeta pretende callar para evitar ser responsable de darlo a conocer (vv. 555-6). El lector queda así, al igual que los personajes y el narrador, comprometido: puede, como César, deleitarse ante el espectáculo, puede lamentarlo y volver horrorizado los ojos, como Pompeyo, también manifestarse indiferente como Júpiter (vv. 445-7), pero tiene asimismo la posibilidad de actuar; la tensión entre las pretensiones de César y las protestas del narrador basta para suscitar una respuesta.

95 No existen demasiados ejemplos de la visita del vencedor al campo de batalla después de la lucha, y estos se intercambian entre los historiadores y poetas (A. Perutelli 2004, p. 86). La descripción se reserva a circunstancias especiales: la derrota romana contra un enemigo extranjero: Cannas (Liv. XXII, Silio X 450), Teutoburgo (Tac., Ann I 61, cf. V. E. Pagan 1999) o, como es el caso en esta ocasión (Sall., Cat 61 y Tac., Hist. II 23.2), a episodios de guerras civiles - tan sólo los cadáveres romanos suscitan el suficiente interés. A. Perutelli 2004, pp. 85-108 resume la cuestión tratada con detalle antes por P. Esposito 1987, pp. 58-9, M. Martina 1991 y M. Gioseffi 1995. La visita de César y Aníbal se parecen, pero Lucano ha tratado de extremar la perversidad del romano, pues Livio matizaba: spolia legenda foedamque etiam hostibus spectandam stragem insistunt (XXII 51.5-6); el César de Lucano, en cambio, lejos de sentir rechazo, se deleita en el espectáculo.

EMERITA (EM) LXXIV 2, julio-diciembre $2006 \quad$ pp. 259-288 ISSN 0013-6662 


\section{Conclusión}

Constatamos que Lucano ha conjugado diversos factores para desvelar, en contra de las dificultades procedentes de la elección como tema de un suceso histórico cuyo final es imposible alterar, la falta de adecuación entre el desenlace final de la batalla y las expectativas de acuerdo con los principios romanos tradicionales. Todo ello busca producir en el lector una impresión de asombro. Posiblemente, con la inclusión de un narratario interno (VIII 17) incapaz de conceder credibilidad al relato de lo sucedido que el propio Pompeyo (K. Ormand 1994) confirma, el poeta no pretende sino anticipar o dirigir la lectura en esa dirección. La coincidencia entre esta proyección implícita hacia el lector de la actitud del narratario interno con la solicitada de forma explícita, mediante la intervención autorial, al narratario externo (VII 212) apoya nuestra opinión. La aproximación, por un lado, a los modelos épicos inadecuados, y, por otro, a los paradigmas narrativos de derrotas romanas le resulta, por diversas razones, de gran utilidad. En primer lugar, demuestra lo sorprendente e injusto de la victoria de César al identificarlo mediante las relaciones intertextuales señaladas con los héroes épicos condenados a la derrota; establece, en segundo lugar, una equivalencia nítida entre César y el enemigo de la patria, al representarlo con los tintes del enemigo más temible de Roma, Aníbal, de ahí su calificación como uictor iniquus (VII 40). Por último, mediante las diferencias perceptibles entre esta derrota y las infligidas a Roma en otros tiempos, libera al vencido de responsabilidad en el desenlace; y como consecuencia de las identificaciones descritas, su propia condición de vencido le redime en parte de la culpa contraída por la participación en la contienda civil y la colaboración en la ruina de la esencia de Roma que el destino ha querido. Las contradicciones resultantes de la comparación con los modelos evocados consiguen hacer más evidente la crueldad de un destino implacable.

REFERENCIAS BIBLIOGRÁFICAS

Ahl, F., 1976, Lucan. An introduction, Ithaca-Londres.

Ahl, F., 1993, «Form empowered: Lucan’s Pharsalia», en A. J. Boyle, ed., Roman Epic, London - New York, pp. 125-42.

Barchiesi, A., 1984, La traccia del modelo. Efetti omerici nella narrazione virgiliana, Pisa.

Bartolomé, J., 1995, Los relatos bélicos en la primera década de AVC de Tito Livio, Vitoria-Gasteiz.

Bartolomé, J., 1996, «La batalla del Alia y sus prolongaciones», Excerpta Philologica 4-5, pp. 149-63.

Bartolomé, J., 2005, «Una aproximación al relato de derrota: la batalla del Trasimeno en Livio», en prensa. Batinski, E., 1992, «Lucan's catalogue of Caesar's tropes», CJ 88, pp. 19-24. 
Codoñer, C., 2003, «Los tres Annaei. La Farsalia trágica», en Gli Annei. Una famiglia nella storia e nella cultura di Roma imperiale. Atti del Convegno internazionale di Milano - Pavia, 2-6 maggio 2000, Como, pp. 303-26.

Delarue, F., 1996, «La guerre civile de Lucain: un épopée plus que pathétique», REL 74, pp. 212-30.

De Nadaï, Ch., 2000, Rhétorique et poétique dans la Pharsale de Lucain. La crise de la représentation dans la poésie antique, Louvain-Paris.

Due, S. 0., 1962, «An essay on Lucan», C\&M 23, pp. 68-132.

Esposito, P., 1978) «Il VII libro della Pharsalia e l'ideologia di Lucano (un'ipotesi interpretativa)», Vichiana 7, pp. 117-41.

Esposito, P., 1987, Il racconto delle strage. Le battaglie nella Pharsalia, Napoli.

Fantham, E., 2003, «The angry poet and the angry gods: problems of theodicy in Lucan's epic of defeat», en S. Braund - G. W. Most, eds., Ancient anger. Perspectives from Homer to Galen, Cambridge, pp. 229-49.

Feeney, D., 1991, The gods in epic. Poets and critics of the classical tradition, Oxford.

Feldherr, A., 1998, Spectacle and society in Livy's History, Berkeley - Los Angeles - London.

Fraenkel, E., 1970 [1927], «Lucan als Mittler des antiken Phatos», en W. Rutz, ed., Wege zu Lucan, Darmstadt, 15-49 (= Vorträge der Bibliothek Warburg 1924-2), pp. 229-357).

Fucecchi, M., 1990, «Il declino di Annibale nei Punica», Maia 42, pp. 151-66.

Fucecchi, M., 1999, «La vigilia di Canne nei Punica e un contributto allo studio dei rapporti fra Silio Italico e Lucano», en L. Nicastri - P. Esposito, eds., Interpretare Lucano. Miscellanea di studi, Nápoles, pp. $305-42$.

Gagliardi, D., 1975, M. Annaei Lucani Belli Ciuilis liber septimus. Testo critico, introduzione, commento a cura di D. Gagliardi, Napoli.

Gioseffi, M., 1995, «La deprecatio lucanea sui cadaveri insepolti a Farsalo (b. civ. VII 825-46)», BStudLat 25, pp. 501-20.

Goebel, G. H., 1981, «Rhetorical and poetical thinking in Lucan's harangues (7.250-382)», TAPhA 111, pp.79-94.

Gormann, B., 2001, «Lucan's epic Aristeia and the hero of the Bellum Civile», CJ96, pp. 263-90.

Gurval, R. A., 1995, Actium and Augustus. The politics of emotions of Civil War, Ann Arbor.

Hardie, Ph., 1986, Virgil's Aeneid: Cosmos and imperium, Oxford.

Helzle, M., 1994, «Indocilis priuata loqui: the characterization of Lucan's Caesar», SO 69, pp. 121-36.

Henderson, J., 1988, «Lucan/ The world at war», en A. J. Boyle, ed., The imperial Muse: Ramus essays on Roman literature of the Empire, to Juvenal through Ovid, Berwick, Australia, pp. 122-64.

Henderson, J., 1998, Fighting for Rome. Poets and Caesars, history and Civil War, Cambridge.

Jal, P., 1962, Les dieux et les guerres civiles dans la Rome de la fin de la République, REL 40, pp.170-200.

Jal, P., 1963, La guerre civile à Rome. Étude litteraire et morale, Paris.

Johnson, W. R., 1987, Momentary monsters. Lucan and his heroes, Ithaca-London.

Kaempfer, J., 1998, Poétique du récit de guerre, Paris.

Labate, M., 1991, «Città morte, città future: un tema della poesia augustea», Maia 43, pp. 167-84.

Lausberg, M., 1985, «Lucan und Homer», ANRW II 32.3, pp. 1565-622.

Lebek, W. D., 1976, Lucans Pharsalia. Dichtungstruktur und Zeitbezug, Göttingen.

Leigh, M., 1997, Lucan. Spectacle and engagement, Oxford.

Lendon, J. E., 1999, «The rhetoric of combat: Greek military theory and Roman culture in Julius Caesar's Battle Descriptions», ClAnt 18, pp. 273-329.

Levene, D. S., 1993, Religion in Livy, Leiden.

Lorenzo Lorenzo, J., 1991, «Lucano, ¿exponente de la pretendida eloquentia Baetica?», en A. Ramos, ed., Mnemosynum C. Codoñer a discipulis oblatum, Salamanca, pp. 175-87.

EMERITA (EM) LXXIV 2, julio-diciembre $2006 \quad$ pp. 259-288 ISSN 0013-6662 
Lounsbury, R. C., 1976, «History and motiv in book seven of Lucan's Pharsalia», Hermes 104, pp. 210239.

Malamud, M., 2003,. «Pompey's head and Cato's snakes», CPh 98, pp. 31-44.

Malcovati, E., 1953, «Lucano e Cicerone», Athenaeum 31, pp. 288-97.

Martina, M., 1991, «Lucano, Bellum Ciuile 7, 825-846», MD 26, pp. 189-92.

Masters, J., 1994, «Deceiving the reader: the political mission of Lucan Bellum Civile 7», en J. Elsner - J. Masters, Reflections of Nero. Culture, history and representation, Duckworth, pp. 151-77.

Mazzochini, P., 2000, Forme e significati della narrazione bellica nell'epos virgiliano. I cataloghi degli uccisi ele morti minore dell'Eneide, Fasano.

Mineo, B., 1997, «L'interprétation livienne de l'histoire: le récit des défaites romaines de la Trébie à Cannes», REL 75, pp. 113-28.

Morford, M. P. 0., 1967, The poet Lucan. Studies in rhetorical epic, Oxford.

Narducci, E., 1979, La provvidenza crudele. Lucano e la distruzione dei miti augustei, Pisa.

Narducci, E., 1985, «Ideología e tecnica allusiva nella Pharsalia», $A N R W$ II 32.31, pp. 538-64.

Narducci, E., 2002, Lucano. Un'epica contro l'impero, Roma - Bari.

Núñez, J. M a , 2002, «La supresión de los deorum ministeria en la Farsalia de Lucano: claves de su pertinencia literaria», ReLat 2, pp. 57-64.

Ormand, K., 1994, «Lucan's Auctor vix fidelis», ClAnt 13, pp. 38-55.

Pagan, V. E., 1999, «Beyond Teutoburg. Trangression and transformation in Tacitus Annales I. 61-62», CPh 94, pp. 302-320.

Perutelli, A., 2004, «Dopo la battaglia: la poetica delle rovine in Lucano (con un'appendice su Tacito)», en P. Esposito y E. M. Ariemma, eds., Lucano e la tradizione dell'epica latina, Napoli, pp. 85-108.

Quint, D., 1993, Epic and empire. Politics and generic form from Virgil to Milton, Princeton.

Radicke, J., 2004, Lucans poetische Technik. Studien zum historischen Epos, Leiden - Boston.

Rambaud, M., 1955, «L'apologie de Pompée par Lucain au livre VII de la Pharsale», REL 33, pp. 258-96.

Rambaud, M., 1960, «L'opposition de Lucain au Bellum Ciuile de César», L'infor. Littér. 12, pp. 258-96.

Rambaud, M., 1980, «Exemples de déformation historique chez Tite-Live. Le Tessin, la Trébie, Trasimène», en R. Chevallier, ed., Colloque Histoire et Historiographie, 1978, Caesarodunum XVbis, París, pp. 109126.

Rosenstein, N., 1990, Imperatores victi. Military defeat and aristocratic competition in the middle and the late Republic, Berkeley - Los Angeles.

Salemme, C., 2000, «Sul ‘senso della storia’ nella Pharsalia di Lucano», BStudLat, 30, pp. 514-29.

Salemme, C., 2004, Lucano, la storia verso la rovina, Napoli.

Schlonski, F., 1995, Studien zum Erzählstandort bei Lucan, Trier.

Sklenář, R., 2003, The taste of nothingness. A study of virtus and related themes in Lucan's Bellum Civile, Ann Arbor.

Spencer, D., 2005, «Lucan’s follies: Memory and ruin in a Civil-War landscape», $G \& R$ 52, pp. 46-69.

Tasler, W., 1972, Die Reden in Lucans Pharsalia, Bonn.

Con arreglo a las normas editoriales vigentes para las publicaciones periódicas del CSIC, se hace constar que el original de este artículo se recibió en la redacción de EMERITA en el primer semestre de 2006, siendo aprobada su publicación en ese mismo período (16.1.06 - 16.5.06)

EMERITA (EM) LXXIV 2, julio-diciembre $2006 \quad$ pp. 259-288 ISSN 0013-6662 